\title{
Três espécies novas de Oligosarcus Günther,1864 e redefinição taxonômica das demais espécies do gênero (Osteichthyes, Teleostei, Characidae)
}

\author{
Naércio A. Menezes \\ Departamento de Zoologia, Instituto de Biociências, USP \\ Bolsista, Conselho Nacional de Desenvolvimento Científico e \\ Tecnológico (CNPq).
}

\section{ABSTRACT}

Three new species of Oligosarcus Günther, 1864 are described and the taxonomy of the previously described species is reviewed. 0 . oligolepis (Steindachner) is resurrected from synonymy and the typelocality of Oligosarcus argenteus Günther is restricted. New diagnoses, synonymies and geographic distributions are provided for all the species and a new key to species is presented.

\section{INTRODUÇÃO}

Após a última revisão do gênero Oligosarcus (Menezes, 1969b), a coleta recente de exemplares do Brasil e da Bolívia possibilitou a descrição de quatro espécies novas (Menezes \& Géry, 1983). O exame de material coletado ainda mais recentemente revelou a presença de mais três espécies novas em algumas regiōes brasileiras. A necessidade de caracterizar e diferenciar estas espécies levou-me a fazer uma revisão das características morfológicas e da distribuição das espécies já descritas. Os resultados obtidos possibilitaram diagnosticar mais 
precisamente todas as espécies, bem como definir melhor suas áreas de distribuição e serviram de base ao estudo recente dos padrões de distribuição das espécies (Menezes, no prelo).

\section{AGRADECIMENTOS}

Pela coleta e envio de exemplares utilizados neste trabalho sou grato a J.R. Verani (Universidade Federal de São Carlos, São Paulo), Verônica Lima da Silva Corrêa (Universidade Estadual do Rio de Janeiro), Carlos Alberto S. de Lucena, Roberto Esser dos Reis, e Luiz Roberto Malarba (Museu de Ciências da Pontifícia Universidade Católica do Rio Grande do Sul, Porto Alegre), Adelinyr A.M. Cordeiro (Departamento de Parques, Praças e Preservação Ambiental, Prefeitura Municipal de Curitiba, Paraná), Mauro César I.B. Ribeiro (Instituto Brasileiro de Geografia e Estatística, Brasilia, D.F.), R.P. Vari (National Museum of Natural History, Smithsonian Institution, Washington, D.C., Estados Unidos) e Cláudio Barra C. (Universidad Mayor de San Simón, Cochabamba, Bolívia).

William L. Fink e Reeve M. Bailey (University of Michigan Museum of Zoology, Ann Arbor, Michigan) permitiram o exame de exemplares depositados na instituição onde trabalham e criaram todas as condições necessárias ao estudo do material.

Parte do material utilizado neste estudo foi coletado durante expedições científicas financiadas pelo Bacon Fund e Neotropical Lowland Research Program da Smithsonian Institution, Washington, D.C., Estados Unidos.

Heraldo A. Britski e José Lima de Figueiredo (Museu de Zoologia da Universidade de São Paulo) leram o manuscrito e apresentaram valiosas sugestões. José Lima Figueiredo compartilhou de inúmeras discussões sobre caracterização das espécies e acompanhou de perto 
todas as fases de desenvolvimento deste trabalho, contribuindo assim decisivamente para sua conclusão.

As fotografias das espécies foram feitas por Luiz Paulo R. Cunha, Fundação Universidade de Rio Grande, Rio Grande do Sul.

\section{MATERIAL E MÉTODOS}

Os exemplares utilizados neste trabalho estão depositados no Museu de Zoologia, Universidade de São Paulo (MZUSP), National Museum of Natural History, Smithsonian Institution, Washington, D.C., Estados Unidos (USNM), University of Michigan Museum of Zoology, Ann Arbor, Michigan, Estados Unidos (UMMZ), British Museum (Natural History), Londres, Inglaterra (BMHN) e Museu de Ciências da Pontifícia Universidade Católica do Rio Grande do Sul, Porto Alegre (MCP).

As medidas e contagens foram feitas de acordo com as especificações contidas em Fink \& Weitzman (1974). Todos os dados morfométricos são expressos em percentagens do comprimento padrão (CP), com exceção das medidas referentes a partes da cabeça, expressas em percentagens do comprimento da cabeça.

Na lista de material examinado, para cada espécie estão incluídas apenas as localidades correspondentes aos exemplares coletados posteriormenteá publicação dos trabalhos de Menezes (1969) e Menezes \& Géry (1983), mas na diagnose e sinonímia de cada espécie estão incluidos também dados contidos nestes trabalhos. Da lista de referências bibliográficas relativas á sinonímia das espécies constam apenas aquelas que não foram citadas nestes mesmos trabalhos.

Os dados merísticos e morfométricos das novas espécies são apresentados nas tabelas 1 e 2. 


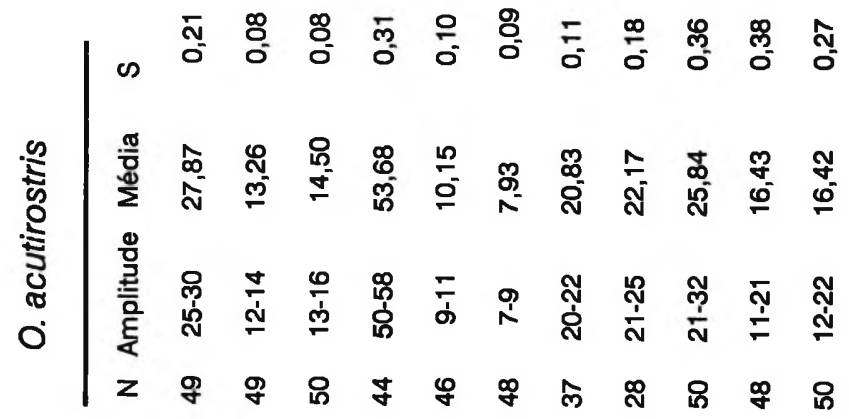

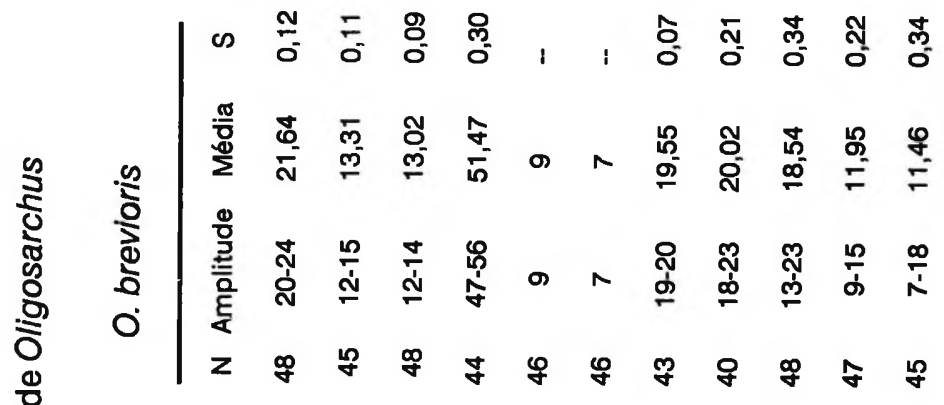

$\frac{\mathscr{0}}{\mathrm{O}}$

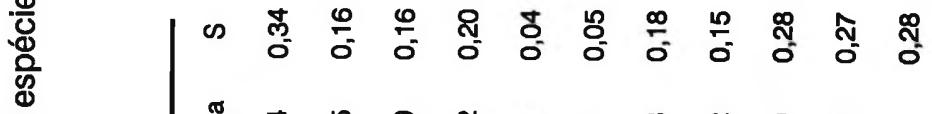

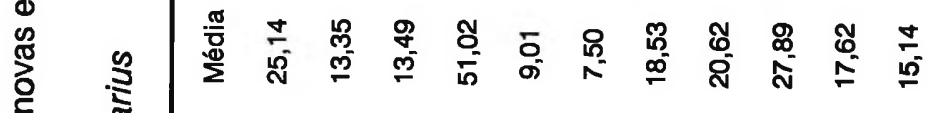

đั

ơ 0

旁

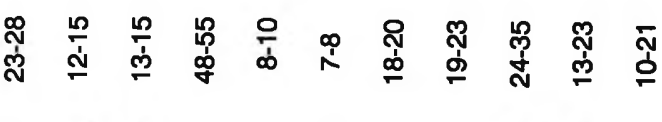

乙

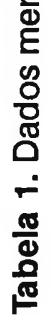

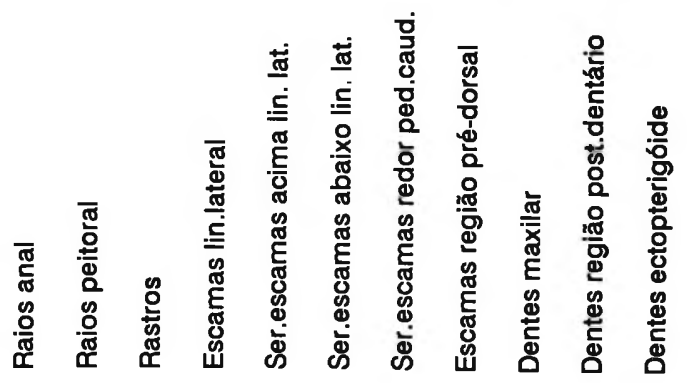




\section{Três espécies novas de Oligosarcus Günther, 1864}

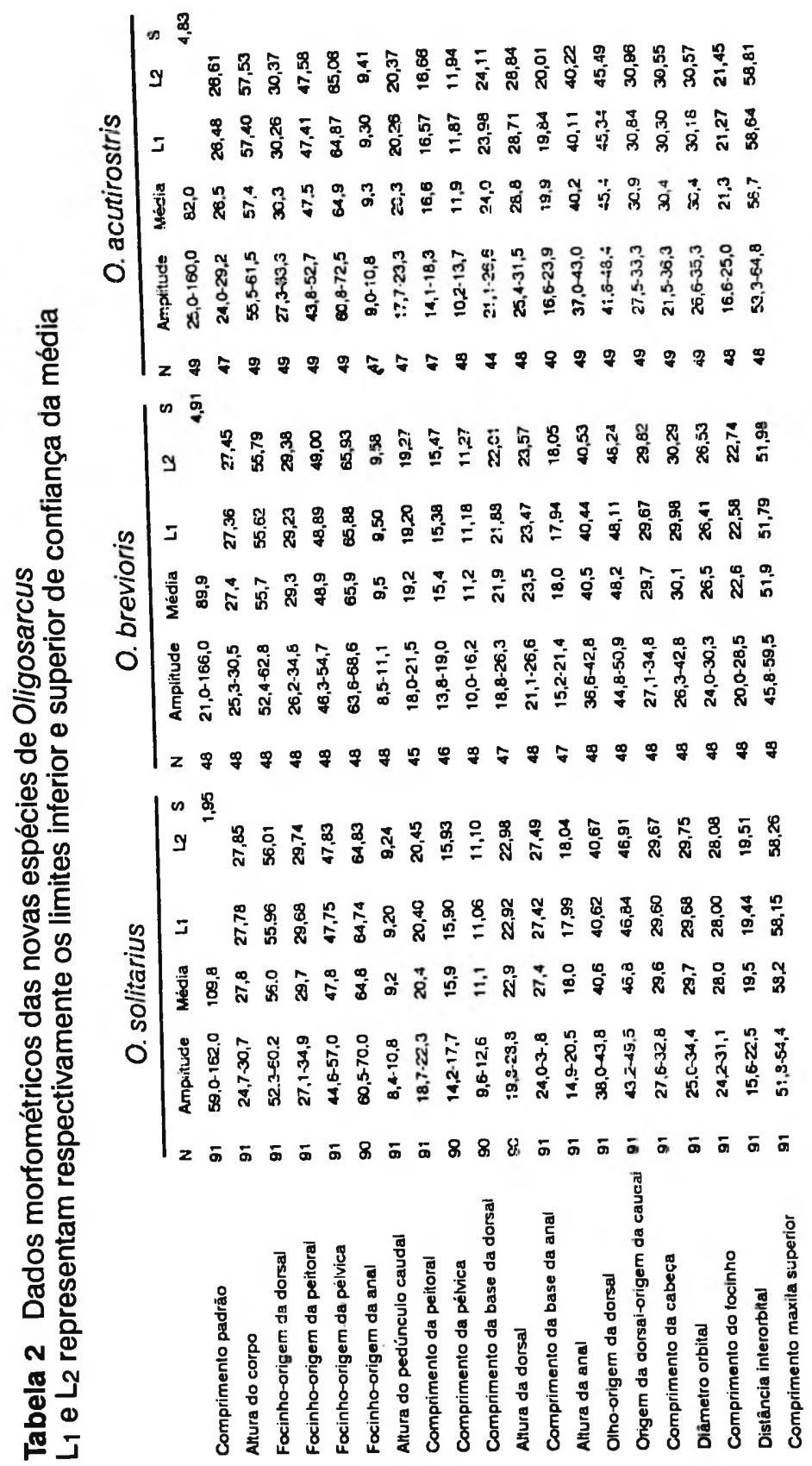




\title{
DESCRIÇÕES DAS NOVAS ESPÉCIES
}

\author{
Oligosarcus solitarius, sp. $\mathbf{n}$.
}

(Fig. 1)

Holótipo MZUSP 37377 (fêmea, 131,0 mm CP), coletado na Lagoa Carioca, Vale do Rio Doce, Minas Gerais (aproximadamente 20을 - 43W), 27 de junho a 14 de julho de 1983 por J. R. Verani.

Parátipos - 39, MZUSP 28982 (19,94,0-160,0 mm, utilizados para obtenção de dados merísticos e morfométricos); 5, USNM 289216 (95,0-118,0 mm): todos coletados com o holótipo. 43, MZUSP 28952 (20,91,0-118,0 mm, utilizados para obtenção de dados merísticos e morfométricos), coletados na Lagoa Belgo Mineira, Vale do Rio Doce, Minas Gerais (aproximadamente 20S - 43W), 05 a 07 de julho de 1983 por J.R. Verani. 11, MZUSP $36638(93,0-116,0 \mathrm{~mm})$ coletados na Lagoa Amarela, Vale do Rio Doce, Minas Gerais (aproximadamente 20S 43W) em 1985 por J.R. Verani. 38, MZUSP 28973 (32, 94,0-162,0 mm utilizados para obtenção de dados merísticos e morfométricos), coletados na Lagoa Dom Helvécio, Vale do Rio Doce, Minas Gerais (aproximadamente 20S - 43W), 25 a 28 de junho de 1983 por J.R. Verani. 7, MZUSP 37401 (59,0-121,0 mm) coletados no Lago Dom Helvécio, Vale do Rio Doce, Minas Gerais, 29 de maio de 1979 por Verônica L. da Silva Corrêa.

Diagnose - Oligosarcus solitarius, sp. n., O. planaltinae Menezes \& Géry, O. macrolepis (Steindachner), O. argenteus Günther e 0. brevioris, sp. n. possuem de 17 a 20 séries horizontais de escamas ao redor do pedúnculo caudal. $O$. solitarius, sp. $n$. difere de $O$. planaltinae e de 0 . argenteus porque possui mais escamas na linha lateral (48-55, ao invés de 38-40 e 44-48, respectivamente). Com relação a 0 . macrolepis, $O$, solitarius, $\mathrm{sp}$. $\mathrm{n}$. possui mais raios na nadadeira peitoral (13-15 ao invés de 12-13 e mais séries horizontais de escamas acima da 
Três espécies novas de Oligosarcus Günther, 1864
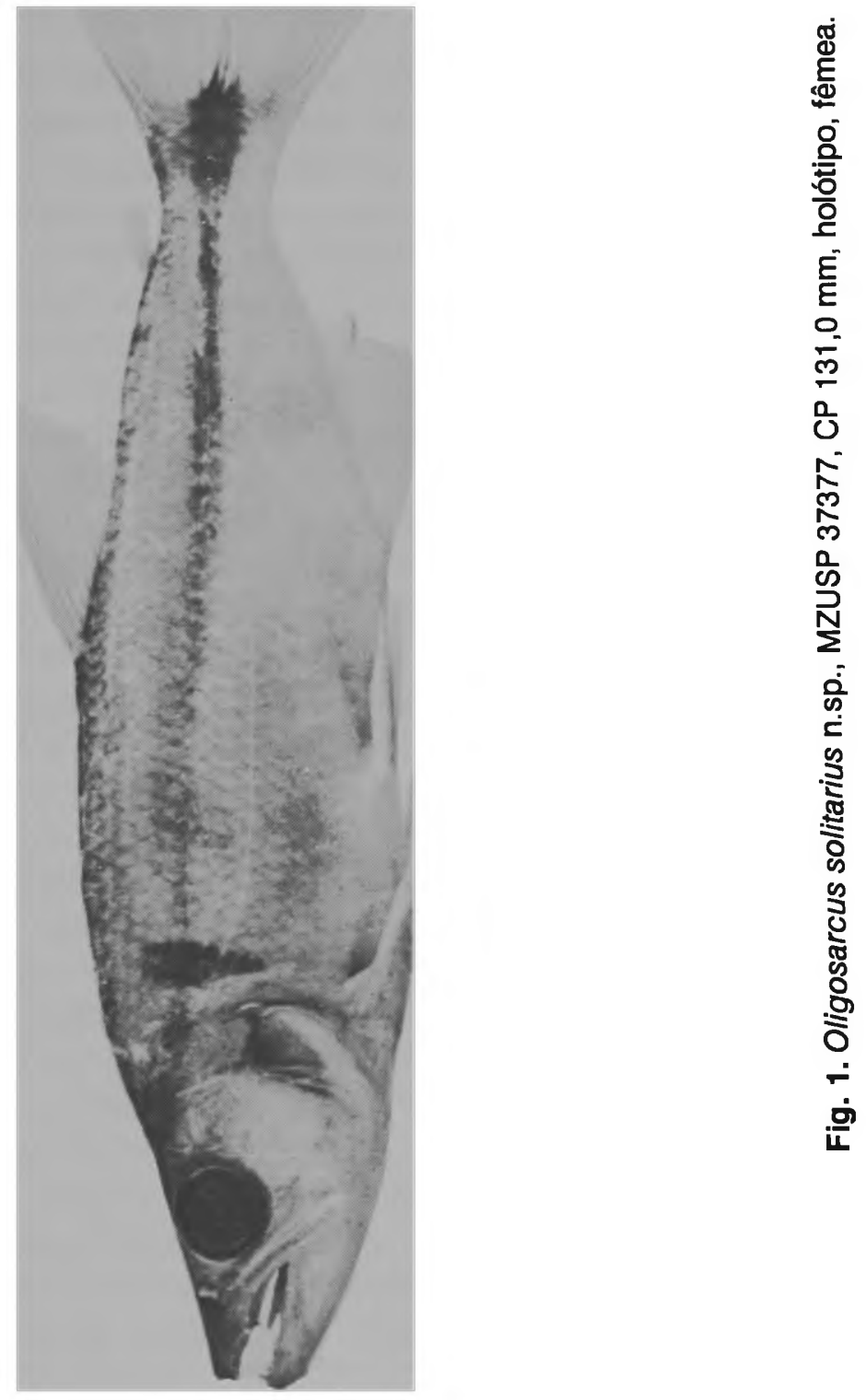
linha lateral (8-10, ao invés de 8) e com relação a 0 . brevioris, sp. $\mathrm{n}$. possui mais raios na nadadeira anal, mais dentes no maxilar e na série posterior do dentário (Tabela 1).

O. pintoi Campos possui apenas 13-16 séries horizontais de escamas ao redor do pedúnculo caudal; todas as demais espécies de gênero possuem entre 20 e 23 (geralmente mais que 20 ) ou muito mais que 23 séries horizontais de escamas ao redor do pedúnculo caudal.

Descrição Corpo moderadamente grande (CP 59,0-162,0 mm) e comprimido, as fêmea atingindo maior comprimento que os machos. Perfís dorsal e ventral do corpo quase igualmente curvos; perfil pré-dorsal convexo da origem da nadadeira dorsal até a região occipital e ligeiramente côncavo desta região até a ponta do focinho. Focinho pontudo, de comprimento igual ao diâmetro orbital nos maiores exemplares, porém menor que este em exemplares com comprimento padrão igual ou inferior a $100 \mathrm{~mm}$; mandíbula mais curta que a maxila superior, os dois dentes caniniformes mais anteriores do pré-maxilar situados para fora quando a boca está fechada. Maxilar curvo, ligeiramente mais largo posteriormente, com 24-35 dentes fracamente tricuspidados, o número de dentes aumentando com o crescimento; parte posterior do maxilar ultrapassando ligeiramente a vertical que passa pela margem posterior da órbita nos maiores exemplares, mas não alcançando esta linha em exemplares com tamanho inferior a 100 $\mathrm{mm}$. Pré-maxilar com um dente caniniforme anteriormente, seguido por 3-5 dentes cônicos pequenos, um dos quais quase sempre é mais desenvolvido e ocupa uma posição mais interna em relação aos demais; segue-se a esta série um dente caniniforme semelhante ao mais anterior e um ou dois pequenos dentes cônicos. Dentário com um caniniforme anterior, seguido por 3 dentes cônicos desenvolvidos e espaçados, de tamanho gradativamente crescente, o último sendo quase caniniforme; a estes segue-se uma série compacta de 13-23 dentes pequenos fracamente tricuspidados. Ectopterigóide com uma série de 10-21 dentes fracamente tricuspidados. Ramo inferior do primeiro arco branquial com 13-15 rastros. 
Linha lateral completa, com 48-55 escamas perfuradas; 8-10 séries horizontais de escamas da linha lateral á origem da nadadeira dorsal, 7-8 da origem anal á linha lateral; 18-20 séries horizontais de escamas ao redor do pedúnculo caudal; 19-23 escamas na região pré-dorsal; uma baínha de escamas ao longo da base anal, formada por uma série de escamas que se estende até a base do décimo raio ramificado desta nadadeira.

Nadadeira dorsal com ii, 9 raios, sua origem mais próxima da base da caudal do que da ponta do focinho. Nadadeira anal com iv- v, 23-28 raios, sua origem situada aproximadamente na vertical que passa pela base do último raio da dorsal; nos machos aparecem espinhos nos raios mais anteriores da anal (em um exemplar com 105,0 mm CP aparecem espinhos na margem do último raio no ramificado e na ramificação posterior dos nove primeiros raios ramificados; o número de espinhos em cada raio ramificado varia de 12 no quarto a apenas 3 no nono); raios ramificados anteriores da anal muito mais longos que os posteriores, tornando a margem da nadadeira anteriormente côncava. Nadadeira caudal com os lobos superior e inferior igualmente desenvolvidos; número de raios principais da caudal $i, 17$, i. Nadadeiras pélvicas com $\mathrm{i}, 7$ raios, a ponta do raio mais longo ultrapassando o ânus mas não atingindo a origem da nadadeira anal; espinhos presentes também nas pélvicas dos machos (na pélvica esquerda ao exemplar acima mencionado aparecem espinhos apenas na parte ventral dos raios ramificados 1 a 4, mas somente no raio 3 aparecem espinhos nos dois ramos; o número de espinhos por ramificação varia de 7 no primeiro a 14 no terceiro raios). Nadadeira peitorais com i, $12-15$ raios, a parte distal do raio mais longo alcançando a origem das pélvicas nos exemplares maiores e ultrapassando esta origem nos menores exemplares.

Cor em álcool marrom a marrom escuro na parte superior da cabeça e do corpo, esta coloração tornando-se gradativamente mais clara nos lados e completamente clara na parte inferior do corpo; focinho marrom escuro, parte pós-orbital da cabeça e opérculo com cromatóforos escuros; mandibula com pigmentos escuros esparsos; 
uma mancha umeral escura verticalmente alongada com a parte superior mais larga e mais intensamente pigmentada, quase negra; esta mancha umeral separada por uma área clara de uma mancha escura difusa e mais larga, às vezes pouco nítida, localizada acima da linha lateral, antes da origem da nadadeira pélvica; uma faixa escura lateral pouco nítida anteriormente, estendendo-se acima da linha lateral até o pedúnculo caudal onde se alarga e torna-se mais escura, quase negra, e prolonga-se como uma faixa estreita sobre os raios médios da nadadeira caudal; nadadeiras claras com pigmentos escuros esparsos, principalmente na caudal, dorsal e anal.

Distribuição 0 . solitarius, $\mathrm{sp}$. $\mathrm{n}$. tem distribuição restrita ao sistema de lagos do Vale do Rio Doce em Minas Gerais. Nenhuma diferença significativa foi encontrada entre as amostras provenientes dos diversos lagos da região.

Etimologia O nome da espécie (do latim solitarius = isolado) é alusivo ao fato de ter sido encontrada em um sistema isolado de lagos no Vale do Rio Doce.

\section{Oligosarcus brevioris, sp. $\mathbf{n}$}

\section{(Fig. 2)}

Holótipo MZUSP 37508 (fêmea, 125,0 mm CP) coletado no Arroio Cachoeirinha, bacia do Rio Pelotas, estrada Vacaria-Bom Jesus, municipio de Vacaria, Rio Grande do Sul (aproximadamente 2840'S 50^40'W), 04 de maio de 1985 por C.A.S. de Lucena, R.E. Reis e L.R. Malabarba.

Parátipos - 19, MZUSP 36489 (46,0-166,0 mm); 17, MCP 6486 $(30,0-140,0 \mathrm{~mm}) ; 17$, USNM 278960 (não utilizados para obtenção de dados merísticos e morfométricos): todos coletados com o holótipo. 2, MZUSP 36493 (21,0-51,0 mm ) coletados no Arroio Passo do Carro, bacia do Rio Pelotas, estrada Vacaria-Bom Jesus, município de Vacaria, Rio 


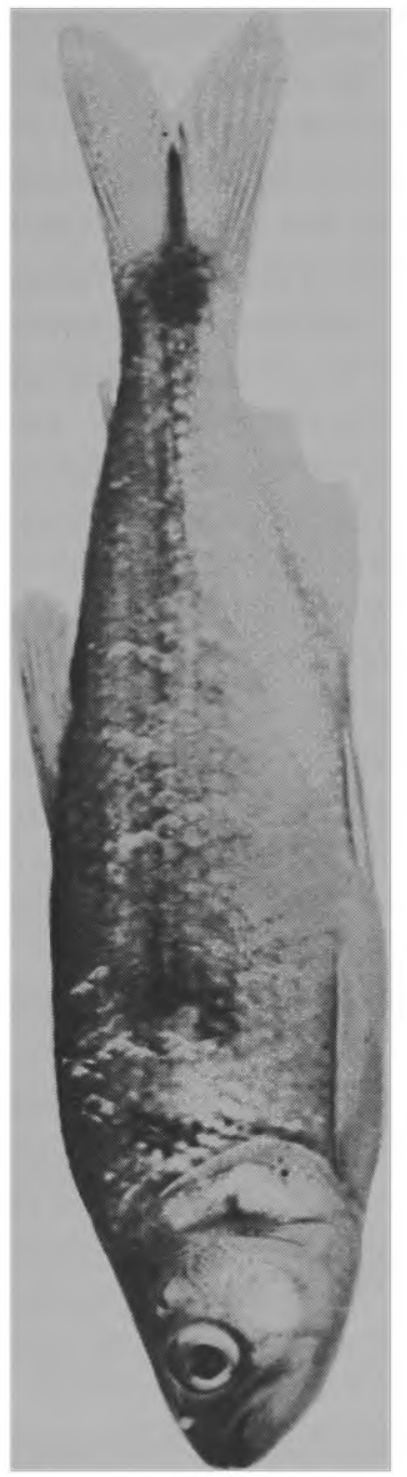

离

E

0

ล

号

$\stackrel{\infty}{0}^{-}$

m

只

$\stackrel{\infty}{2}$

$\sum^{N}$

웅

c

co

은

(1)

อ

3

O

ฐ

옹

i

흔 
Grande do Sul, 04 de maio de 1985 por C.A.S. de Lucena, R.E. dos Reis e L.R. Malabarba, 4, MZUSP 36492 (21,5-88,0 mm) 2, USNM 278965 (não utilizados para obtenção de dados merísticos e morfométricos), coletados no Arroio Lageado Bonito, bacia do Rio Pelotas, estrada Vacaria-Bom Jesus, município de Vacaria, Rio Grande do Sul, 04 de maio de 1985 por C.A.S. de Lucena, R.E. dos Reis e L.R. Malabarba, 5, MCP $10968(38,0-118,0 \mathrm{~mm})$ coletados em um arroio afluente do Rio Uruguai, estrada Guarita-Pinheiros, Palmitinho, Rio Grande do Sul, 22 de dezembro de 1985 por C.A.S. de Lucena,R.E. dos Reis e L.R.Malabarba.

Diagnose Oligosarcus brevioris, sp. n., está incluida entre as espécies que possuem 20 ou menos séries horizontais de escamas ao redor do pedúnculo caudal, diferindo assim de todas as outras espécies que possuem mais que 20 séries. Difere de $O$. pintoi Campos, $O$. macrolepis (Steindachner) e O. planaltinae Menezes \& Géry, porque estas possuem entre 13 e 18, ao invés de 19-20 séries horizontais de escamas ao redor do pedúnculo caudal. $O$. argenteus Günther e $O$. solitarius, sp. $\mathrm{n}$. também possuem até 20 séries horizontais de escamas ao redor do pedúnculo caudal, mas a primeira possui menos escamas perfuradas na linha lateral $(44-48, \bar{x}=46,66)$ do que $O$. brevioris sp. $n$. $(47-56, \bar{x}=51,47)$; as diferenças em relação a $O$. solitarius $\mathrm{sp}$. n. são discutidas na diagnose daquela nova espécie.

Em O. schindleri Menezes \& Géry, O. paranensis Menezes \& Géry, O. longirostris Menezes \& Géry e $O$. acutirostris, sp. $\mathrm{n}$. o número minimo de séries horizontais de escamas ao redor do pedúnculo caudal (20) equivale ao número máximo destas séries em $O$. brevioris, sp. $n$. Entretanto, $O$. schindleri tem menos raios na anal (17-19, ao invés de 20-24), O. paranensis e $O$. longirostris têm mais dentes no maxilar (18-35, $\bar{x}=25,3$ e 24-32, $\bar{x}=27,0$, respectivamente, ao invés de $13-23, \bar{x}=$ $18,54)$ e $O$. acutirostris sp. $n$., tem mais raios na nadadeira anal $(25-30$, ao invés de 20-24).

Maxilar curto, nunca alcançando a linha vertical que passa pela margem posterior da órbita. 
Descrição Corpo moderamente grande (CP 21,0-166,0 mm), as fêmeas alcançando maior tamanho que os machos. Perfís dorsal e ventral quase igualmente curvos; perfil pré-dorsal regularmente convexo, apenas com uma depressão pouco acentuada na região interorbital. Focinho cônico, de comprimento pouco menor que o diâmetro orbital nos pequenos exemplares, igual ao diâmetro orbital nos exemplares de porte médio e grande; mandíbula robusta, com perfil ventral acentuadamente convexo, apenas ligeiramente mais curta que a maxila superior, os dois dentes caniniformes do pré-maxilar visíveis externamente sobre dois pequenos sulcos na parte anterior da mandibula quando a boca está fechada. Maxilar curto, mais largo posteriormente, sua extremidade posterior alcançando apenas até a vertical que passa pelo meio do olho nos pequenos exemplares, nunca atingindo a linha vertical que passa pela margem posterior da órbita nos maiores exemplares; uma série variável de 13-23 dentes fracamente tricuspidados no maxilar; número de dentes do maxilar não aumentando com o crescimento como nas outras espécies do gênero. Pré-maxilar com um caniniforme anterior seguido de 3-4 dentes fracamente tricuspidados, um caniniforme semelhante ao primeiro e 1-2 dentes cônicos; internamente há um dente cônico de tamanho semelhante aos dois últimos dentes do pré-maxilar. Dentário com um caniniforme anterior seguido de 3 dentes cônicos desenvolvidos com aproximadamente o mesmo tamanho, todos côncavos para dentro, ás vezes com uma pequena saliência de cada lado que não chega a representar uma cúspide verdadeira; segue-se uma série compacta de 9-15 dentes fracamente tricuspidados. Ectopterigóide com uma série de 7-18 dentes fracamente tricuspidados. Em exemplares muito jovens (30-35 mm CP) todos os dentes têm a forma aproximadamente cônica, não existindo as cúspides rudimentares que caracterizam os dentes do maxilar, ectopterigóide e alguns dentes do pré-maxilar e do dentário. Ramo inferior do primeiro arco branquial com 12-14 rastros.

Nadadeira dorsal com ii, 9 raios, sua origem mais próxima á base da caudal do que da ponta do focinho. Nadadeira anal com iv-v, 20-24 
raios, sua origem situada posteriormente á vertical que passa pela base do último raio dorsal: raios mais anteriores da anal com espinhos nos machos (em um exemplar com $105,0 \mathrm{~mm}$ os espinhos estão concentrados na margem posterior do último raio não ramificado e na ramificação posterior dos oito raios ramificados mais anteriores; o número de espinhos em cada raio varia de 2 no oitavo a 14 no terceiro raios ramificados); raios ramificados mais anteriores da anal mais longos que os demais, formando um lobo pouco pronunciado. Lobos da nadadeira caudal igualmente desenvolvidos; raios principais da caudal i, 17. i. Nadadeiras pélvicas com i, 7 raios, a extremidade dos raios mais longos alcançando e às vezes ultrapassando o ânus mas não atingindo a origem da nadadeira anal; machos com espinhos nas pélvicas (na pélvica esquerda do exemplar mencionado anteriormente aparecem espinhos apenas na parte ventral dos raios ramificados 1 a 6 , distribuidos do seguinte modo: 11 espinhos apenas na ramificação interna do primeiro raio, 12 apenas na ramificação interna do segundo raio, 3 na parte basal da ramificação externa e 10 na parte apical da ramificação interna do terceiro raio, 10 na parte basal da ramificação externa e 9 na parte apical da ramificação interna do quarto raio, 11 na parte basal da ramificação externa e 5 na parte apical da ramificação interna do quinto raio e apenas 4 na parte basal da ramificação externa do sexto raio).

Nadadeiras peitorais com i, 12-15 raios, a extremidade dos raios mais longos nunca alcançando a origem das pélvicas, consideravelmente mais distante desta origem nos exemplares maiores.

Linha lateral completa, com 47-55 escamas perfuradas; 9 séries horizontais de escamas acima da linha lateral, 7 abaixo; 19-20 séries horizontais de escamas ao redor do pedúnculo caudal; 18-23 escamas na regio pré-dorsal; baínha de escamas ao longo da base da nadadeira anal formada por apenas uma série de escamas de cada lado que se estende aproximadamente até a base do oitavo raio ramificado desta nadadeira.

Coloração geral em álcool prateada, consideravelmente mais escura superiormente e mais clara inferiormente; parte superior da 
cabeça e focinho enegrecidos, esta coloração estendendo-se como uma estria ao longo do maxilar até pouco mais de sua metade; parte pós-orbital da cabeça e opérculo com pontuações escuras; uma mancha enegrecida na região umeral, mais larga superiormente e estreitando-se gradativamente para baixo,separada de uma mancha maior, menos escura e difusa, situada acima da linha lateral, pouco antes da origem da nadadeira pélvica; uma faixa prateada escura estendendo-se lateralmente da parte póstero-superior do opérculo até a base da nadadeira caudal, tornando-se mais larga e escura na região do pedúnculo caudal e prolongando-se até a extremidade dos raios médios da caudal; nadadeiras claras, a dorsal e a caudal densamente pigmentadas de escuro, as demais com pigmentos escuros esparsos.

Distribuição Esta espécie foi coletada apenas em afluentes do Rio Pelotas e na parte alta do Rio Uruguai, no Rio Grande do Sul, o que faz supor que sua distribuição esteja limitada à bacia do Alto Uruguai.

Etimologia - O nome brevioris deriva do latim brevis (curto) e oris (boca) e é relativo ao tamanho proporcionalmente menor da abertura bucal desta espécie em relação às demais do gênero.

\section{Oligosarcus acutirostris, sp. $\mathbf{n}$.} (Fig. 3)

Xiphorhynchus hepseticus, Castelnau, 1855:75 (Bahia).

Oligosarcus jenynsii; Menezes, 1969b: 16 (apenas exemplares de Cachoeiro do Itapemirim, Rio Doce, Rio Santa Maria, Rio São José e Rio São Mateus, Espirito Santo; Rio Doce, Minas Gerais; Rio Mucuri, Santa Clara e Belmonte, Bahia).

Holótipo - MZUSP 37525 (macho, 104,0 mm CP), coletado no Rio Itapemirim, Fazenda Boa Esperança, entre Pacotuba e Coutinho, Espirito 
Santo (aproximadamente $21^{\circ} \mathrm{S} 41^{\circ} \mathrm{W}$ ), 13 de novembro de 1982 por Naércio A. Menezes, Stanley H. Weitzman e Marilyn Weitzman.

Parátipos 5, MZUSP 27582 (4, 32,0-104,0 mm utilizados para obtenção de dados merísticos e morfométricos); 5, USNM 289217 (25,0-105,0mm): todos coletados com o holótipo. 2 MZUSP 27573 (89,0-124,0 mm), 3, USNM $289218(26,0-36,0 \mathrm{~mm})$, coletados no Rio São José das Torres, BR-101, entre Campos, Rio de Janeiro e Cachoeiro do Itapemirim, Espirito Santo, 12 de novembro de 1982 por Naércio A. Menezes, Stanley H. Weitzman e Marilyn Weitzman, 1, MZUSP 4765 (77,0 $\mathrm{mm}$ ), coletado no Rio do Frade e da Freira, município de Cachoeiro do Itapemirim, Espirito Santo, 30 de janeiro de 1965 por Heraldo A. Britski e Izaurio A. Dias. 2, MZUSP 4783 e 1795 (77,0 e 122,0 mm), coletados no Rio Santa Maria da Vitória, Espirito Santo, 1912 por E. Garbe. 3, MZUSP 3307, 4770-71 (118,0-123,0 mm), coletados no Rio São José, Espirito Santo, novembro de 1942 por Olivério Pinto, 1, MZUSP 19653 (76,0 mm), coletado na Lagoa Juparanã, Linhares, Espirito Santo, 3-9 de fevereiro de 1965 por Heraldo A. Britski e Izaurio A. Dias. 2, MZUSP 19652 (46,0-60,0 mm), coletados na Lagoa Nova, Linhares, Espírito Santo, 3 de fevereiro de 1965 por Heraldo A. Britski e Izaurio A. Dias. 1, MZUSP 19511 (79,0 mm), coletado na Lagoa Jupuranã, Linhares, Espírito Santo, janeiro de 1964 pela Expedição do Departamento de Zoologia da Secretaria da Agricultura do Estado de São Paulo. 12, MZUSP 1686, 4772-82 (80,0-160,0mm), coletados no Rio Doce, Espírito Santo, 1906 por E. Garbe. 1, MZUSP $4785(66,0 \mathrm{~mm})$, coletado no Rio Doce, Minas Gerais por Olivério Pinto. 11, MZUSP 2798, 37563-67, 4796-4800 (66,0-101,0 mm), coletados em Belmonte, Bahia, 1919 por E. Garbe. 1, MZUSP $37568(99,0 \mathrm{~mm})$, coletado em riacho na estrada Prado-Cumuruxatiba, munícipio de Prado, Bahia, 19 de março de 1985 por Naércio A. Menezes, Stanley H. Weitzman Marilyn Weitzman e Ricardo M. C. Castro.

Diagnose É semelhante a $O$. paranensis Menezes \& Géry, $O$. longirostris Menezes \& Géry e $O$. schindleri Menezes \& Géry que também possuem entre 20 e 22 séries horizontais de escamas ao redor 
Três espécies novas de Oligosarcus Günther, 1864
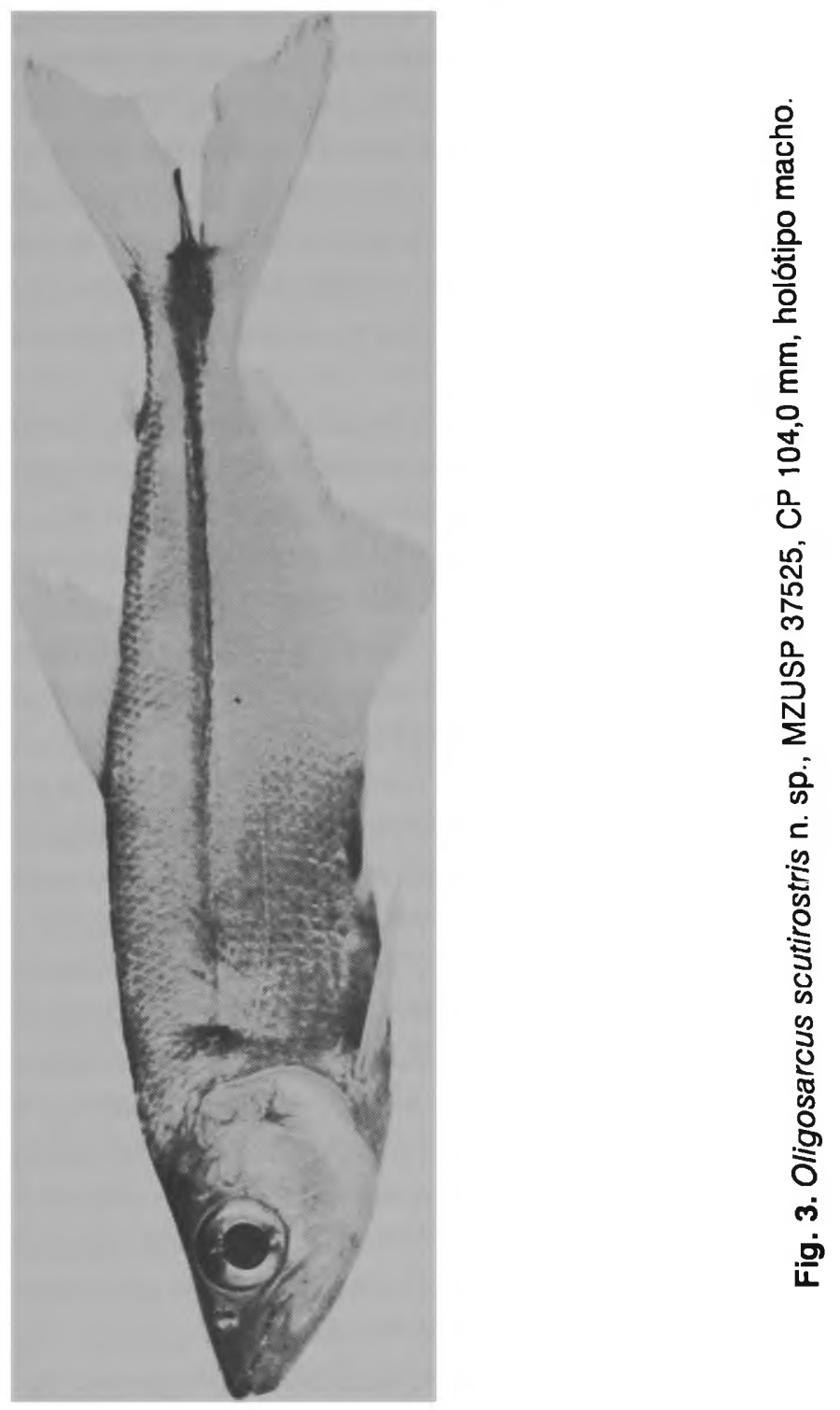
do pedúnculo caudal, mas difere dessas espécies porque possui 25-30 $\bar{x}=27,87)$ raios na nadadeira anal, ao invés de $17-19 \mathrm{em} \mathrm{O}$. schindleri, 20-27 $(\bar{x}=22,70)$ em O. paranensis e 22-26 $(\bar{x}=24,0)$ em O. longirostris. 0 . jenynsii (Günther) possui entre 21 e 23 séries horizontais de escamas ao redor do pedúnculo caudal mas difere de $O$. acutirostris, sp. n. porque possui menos raios na anal $(21-27, \bar{x}=24,45)$. As demais espécies possuem muito menos ou em média menos que 20 e muito mais ou em média mais que 22 séries horizontais de escamas ao redor do pedúnculo caudal.

Descrição - Corpo moderadamente grande (CP 25,0-160,0 mm), as fêmeas alcançando maior comprimento que os machos. Perfil ventral quase regularmente convexo da ponta da mandíbula até a região do pedúnculo caudal; perfil dorsal retilíneo da ponta do focinho à região interorbital,com uma concavidade pouco acentuada na região occipital, tornando-se convexo desta região até a origem da nadadeira dorsal e descendo em linha inclinada um pouco sinuosa deste ponto até a região do pedúnculo caudal. Focinho cônico, acentuadamante agudo, de comprimento pouco menor que o diâmetro orbital nos exemplares com comprimento inferior a $40 \mathrm{~mm}$, igual ao diâmetro orbital nos exemplares entre 50 e 100 mm e muito mais longo que o diâmetro orbital nos exemplares maiores que $100 \mathrm{~mm}$; mandíbula um pouco mais curta que a maxila superior, os dois caniniformes anteriores do pré-maxilar permanecendo fora da abertura bucal e não tocando a ponta da mandíbula quando a boca está cerrada. Maxilar moderadamente curvo, mais largo posteriormente, sua extremidade posterior alcançando a vertical que passa pela margem posterior da pupila nos pequenos exemplares e a vertical que passa pela margem posterior da órbita nos grandes exemplares; uma série de 21-32 dentes maxilares fracamente tricuspidados, o número de dentes aumentando com o crescimento. Prémaxilar com um caniniforme anterior, seguido de 3-5 dentes aproximadamente cônicos, um caniniforme ligeiramente menor que o primeiro e 1-2 dentes cônicos; mais internamente há um dente cônico um pouco maior que os dentes aproximadamente cônicos situados mais 
externamente. Dentário com um caniniforme anterior seguido de 3 dentes cônicos desenvolvidos, o último dos quais de tamanho quase igual ao caniniforme anterior; segue-se uma série compacta de 11-21 dentes fracamente tricuspidados. Ectopterigóide com uma série de 12-22 dentes fracamente tricuspidados. Nos jovens com tamanho inferior a $40 \mathrm{~mm}$ todos os dentes são aproximadamente cônicos. Ramo inferior do primeiro arco branquial com 13-16 rastros.

Nadadeira dorsal com ii,9 raios, sua origem mais próxima da base da caudal do que da ponta do focinho. Nadadeira anal com iv-v, 25-30 raios, sua origem situada aproximadamente na vertical que passa pela base do último raio da dorsal; espinhos presentes nos 8 primeiros raios ramificados da anal nos exemplares machos, localizados apenas nas ramificações posteriores (em um exemplar com 143,0 mm o número de espinhos por raio varia de 3 no oitavo a 12 no quarto, quinto e sexto raios ramificados); último raio não ramificado e raios ramificados mais anteriores mais longos que os demais, formando um lobo anterior pouco pronunciado. Nadadeira caudal com lobos igualmente desenvolvidos; número de raios principais da caudal, i, 17, i; nadadeiras pélvicas com i,7 raios, a extremidade dos raios mais longos ultrapassando o ânus mas não alcançando a origem da nadadeira anal; espinhos presentes nas pélvicas dos machos (na pélvica esquerda do exemplar acima mencionado aparecem espinhos na parte ventral de todos os raios ramificados, de acordo com a seguinte disposição: 10 espinhos apenas na ramificação interna de primeiro raio, 14 apenas na ramificação interna do segundo raio, 13 apenas na ramificação interna do terceiro raio, 5 na parte basal da ramificação externa e 11 na parte apical da ramificação interna do quarto raio, 3 na parte basal da ramificação externa e 4 na parte apical da ramificação interna do quinto raio, 2 na parte basal da ramificação externa do sexto raio e 4 na parte basal da ramificação externa do sétimo raio). Nadadeiras peitorais com i, 12-14 raios, a extremidade dos raios mais longos ultrapassando a origem das pélvicas.

Linha lateral completa, com 50-58 escamas perfuradas; 9-11 séries horizontais de escamas acima da linha, 7-9 abaixo; 20-22 séries 
horizontais de escamas ao redor do pedúnculo caudal; 21-25 escamas na região pré-dorsal; baínha de escamas ao longo da base da anal constituida por uma série de escamas de cada lado que se extende até a área compreendida entre as bases do décimo quinto e décimo sétimo raios ramificados desta nadadeira.

Cor em álcool marrom clara na parte superior do corpo, tornandose gradativamente mais clara nos lados e inferiormente; parte superior da cabeça e focinho mais escuros que o restante do corpo; parte pós-orbital da cabeça, parte posterior da mandíbula e opérculo prateados; uma mancha umeral negra, mais larga superiormente, estreitando-se gradativamente para baixo; uma faixa lateral prateada estendendo-se até a região do pedúnculo caudal onde se torna mais larga e escura, prolongando-se até a extremidade dos raios médios da caudal; nadadeiras claras, com alguma pigmentação escura principalmente na caudal, dorsal e parte anterior da anal.

Distribuição - O. acutirostris, sp. n., ocorre nos rios e lagoas da região costeira do Brasil compreendida entre o estado do Espírito Santo e o sul da Bahia.

Etimologia O nome da éspecie deriva do latim acutus (agudo) e rostrum (focinho) e é relacionado à forma acentuadamente aguda do focinho.

\section{REDEFINIÇÃO TAXONÔMICA DAS ESPÉCIES}

\section{Oligosarcus pintoi Campos, 1945}

Oligosarcus pintoi Campos, 1945:456 (localidade-tipo: Rio MogiGuaçu, São Paulo); Fowler, 1950:326 (sinonímia); Fernandez-Yepez, 1955:6 (diagnose, distribuição); Gomes \& Monteiro, 1955:82-154; 
Schubart, 1962:27 (rio Mogi-Guaçu, São Paulo, citação); Menezes \& Géry, 1983:588, 592 (diagnose em chave; novas ocorrências).

Paroligosarcus pintoi; Menezes, 1969a: 218, 220; 1969b: 12-14 (sinonímia, descrição, distribuição); Godoy, 1975:229 (sinonímia, diagnose, distribuição, biologia, pesca, alimentação); Ringuelet, 1975:58 (citação).

Hemibrycon marciae Godoy, 1971: 153-159 (localidade-tipo: rio Mogi-Guaçu, São Paulo).

Material examinado (23) - USNM 24730 (1); Rio Carapa, acima das cachoeiras, Canendiyu, Paraguai; USNM 247315 (1): Arroyo Primaveira, $4 \mathrm{~km}$ acima do Arroyo Guazu-Ri, Canendiyu, Paraguai; USNM 247316 (1): Arroyo Guazu-Ri, Canendiyu,Paraguai; UMMZ 206421 (20): lagoa no Balneário Municipal, $1,3 \mathrm{~km}$ a oeste do Salto del Guaira, Paraguai.

Diagnose - Nadadeira anal iv-v, 24-28; peitoral i, 13-16; 36-40 escamas perfuradas na linha lateral; 7-9 séries horizontais de escamas acima da linha lateral, 6-8 abaixo; 14-18 escamas na região pré-dorsal; 13-16 séries horizontais de escamas ao redor do pedúnculo caudal; 12-15 rastros no ramo inferior do primeiro arco branquial; $15-23$ destes no maxilar; 10-18 dentes na região posterior do dentário; 5-14 dentes no ectopterigóide.

Distribuição Riachos e lagoas da bacia do Alto Paraná nos estados de São Paulo e Minas Gerais e no Paraguai.

\section{Oligosarcus macrolepis (Steindachner, 1876)}

Xiphorhamphus macrolepis Steindachner, 1876:594 (localidadetipo: Rio Jequitinhonha; Eigenmann \& Eigenmann, 1891: 58 (citação).

Acestrorhamphus macrolepis; Eigenmann, 1910:447 (citação); Fowler,1950:326 (sinonímia); Fernandez-Yepez, 1955:5 (diagnose). 
Oligisarcus macrolepis; Menezes, 1969b: 29 (sinonímia, descrição,distribuição); Menezes \& Géry, 1983: 589 (diagnose em chave).

Material examinado (3) - MZUSP 37255: Lagoa marginal do Rio Jequitinhonha no km 205 da estrada Salto da Divisa Jacinto, Minas Gerais.

Diagnose Nadadeira anal iv-v, 25-27; peitoral i, 12-13; 44-46 escamas perfuradas na linha lateral; 8 séries horizontais de escamas acima da linha lateral, 6-7 abaixo; 17-19 escamas na região pré-dorsal; 17-18 séries horizontais de escamas ao redor do pedúnculo caudal; 11-14 rastros no ramo inferior do primeiro arco branquial; 19-25 dentes no maxilar; 12-20 dentes na região posterior do dentário; 11-14 dentes no ectopterigóide.

Distribuição - Alto e médio Jequitinhonha em Minas Gerais.

\section{Oligosarcus argenteus Günther, 1864}

Oligosarcus argenteus Günther, 1864: 353 (localidade-tipo: Brasil; tipos (BMNH) examinados: Eigenmann \& Eigenmann, 1891: 58 (citação); Eigenmann, 1910: 447 (citação); Campos, 1945b: 479 (citação); Campos \& Trawavas, 1949: 158 (redescrição. dos exemplares de Günther); Fowler, 1950: 326 (sinonímia); Fernandez-Yepez, 1955: 6 (diagnose).

Oligosarcus meadi Menezes, 1969a: 31 (localidade-tipo: União de Caeté, Minas Gerais, bacia do Rio das Velhas; Menezes \&Géry, 1983: 589 (diagnose em chave).

Acestrorhamphus sp. B. Menezes, 1969a: 219, 221.

Material examinado (48) - MZUSP 37154 (10): ribeirão afluente do Rio Paraopeba, Pedra Vermelha, município de Moeda, Minas Gerais; MZUSP 37256 (35): Rio Piranga, Viçosa, Minas Gerais: MZUSP 19573 
(1): lagoa na Serra do Caraça, Minas Gerais; MZUSP 1703 e 4613 (2): Ribeirão do Carmo, Mariana, Minas Gerais.

Diagnose - Nadadeira anal iv-v, 20-25; peitoral i, 11-14; 44-48 escamas perfuradas na linha lateral; 8-9 séries horizontais de escamas acima da linha lateral, 6-8 abaixo; 17-20 escamas na região pré-dorsal; 17-20 séries horizontais de escamas ao redor do pedúnculo caudal; 11-14 rastros no ramo inferior do primeiro arco branquial; 17-24 dentes no maxilar; 10-19 dentes na parte posterior do dentário; 8-15 dentes no ectopterigóide.

Distribuição Riachos formadores da drenagem do Rio Doce e da drenagem do Rio das Velhas em Minas Gerais, Brasil.

N O T A Embora a localidade-tipo de O. argenteus não seja conhecida com exatião, considero que ela esteja incluída na área de distribuição acima citada. O material (dois exemplares), depositado no Museu Britânico, que serviu de base à descrição original da espécie é provavelmente originado do Rio Cipó, afluente do Rio das Velhas em Minas Gerais, pois exemplares de outra espécies brasileiras descritas na mesma época por Günther (1861) foram coletadas naquele rio. Tanto o holótipo como o parátipo apresentam caracteristicas morfológicas idênticas a do restante do material examinado.

\section{Oligosarcus jenynsii (Gunther, I864)}

Hydrocyon hepsetus (non Cuvier, 1829: 312) Jenyns, I842: 129 (lago em Maldonado, Uruguai).

Xiphorhamphus jenynsii Gunther, 1864: 356 (localidade-tipo: lago em Maldonado); Steindacher, 1869: 299 (Montevidéu); 1891: 371 (parte; apenas os exemplares do Arroyo Miguelete, Uruguai); Hensel, 1870: 89 (Rio Guaiba, Porto Alegre; descrição); Holmberg, 1889: 366 (arroios e rios da Provincia de Buenos Aires, Rio de la Plata; Rio Uruguai); 1893: 88 
(citação). Eigenmann, 1894 : 635 (Rio Grande do Sul, Brasil; citação); 1910: 447 (citação); Evermann \& Kendall, 1907: 84 (Argentina).

Acestrorhamphus jenynsii; Eigenmann \& Ogle, 1907: 35 (La Paz, Montevidéu, Uruguai); Eigenmann, 1910: 447 (citação); Fowler, 1950: 325-326 (sinonímia); Fernandez-Yepez, 1955: 5 (diagnose); Menezes, 1969a: 218, 221 (hábitos alimentares).

Acestrorhynchus jenynsii; De Buen, 1950: 85.

Oligosarcus jenynsii; Menezes 1969b: 16-26 (em parte; apenas os exemplares do Rio Grande do Sul, Brasil e Uruguai); Menezes \& Géry, 1983: 589 (diagnose em chave); Miquelarena, 1986: 13-15 (dentição).

Acestrorhynchus jenynsi; Devicenzi, 1924: 178 (Arroyo Miguelete; diagnose).

Acestrorhamphus jenynsi; Mac Donagh, 1931: 255-289 (citação); 1934a: 49 (citação); 1934b: 183-197 (Laguna Alsina, Argentina); Pozzi, 1945: 257 (citação); Aramburu, 1953: 308 (descrição); Ringuelet, Olivier, Guarrera \& Aramburu, 1955: 72 (Laguna Monte,Buenos Aires); Ringuelet \& Aramburu, 1957: 12 (Provincia de Buenos Aires até Vantania); 1962: 32 (citação); Olivier, 1961: 47 (Vitel, Buenos Aires); Ringuelet, Aramburu \& Aramburu, 1967: 175 (descrição; distribuição); Ringuelet, 1975: 48, 53, $54,61,65,68,79,88,90$ (citações).

Acestrorhamphus jenynsi; Mac Donagh, 1930: 231 - 233 (Laguna Cochicó, Argentina).

Xiphorhamphus brachycephalus Cope, 1894: 84 (localidade-tipo: Rio Grande do Sul, Brasil); Ihering, 1937: 21 (diagnose).

Sphyraenocharax brachycephalus; Fowler, 1906: 84 (síntipos de Cope); 1950: 326 (Rio Grande do Sul; sinonímia).

Acestrorhamphus brachycephalus; Eigenmann, 1907: 452 (La Plata; diagnose); 1910: 447 (citação); Fernandes-Yepez, 1955: 5(diagnose).

Acestrorhamphus purpureus Messner, 1962: 1-5 (localidade-tipo: Rio Olimar, Montevidéu); Riguelet, Aramburu \& Aramburu, 1967: 179 (citação). 
Material examinado (21): Rio Grande do Sul MZUSP 19971 (3) e 19974 (1), riacho perto da Fazenda Caçapava, Taim; MZUSP 37262 (2), Arroio do Salso, estrada Livramento - Rosário do Sul, Rosário do Sul; MZUSP 19448 (3), Riacho Passo Comprido em Passo da Areia, município de Viamão; MZUSP 20530 (1), Barragem da Lomba do Sabão, município de Viamão. MZUSP 9617 (3), Pelotas; MZUSP 20258 (2), Arroio Três Passos, afluente do Rio Jacuí; MZUSP 20001 (1), Lagoa Mirim, Ponta Alegre; MZUSP 25340 (1), Rio Jacuí, Barragem de Ernestina, perto de Passo Fundo; MZUSP 19684 (1), Vapor Velho, Montenegro; MZUSP 19920 (1), Rio Forqueta, Marquês de Souza; MZUSP 19944 (2), Arroio Fiuza, em Passo do Fiuza, Município de Viamão.

Diagnose Nadadeira anal iv-v, 21-27; peitoral i, 13-14; 54-62 escamas perfuradas na linha lateral; $10-11$ séries horizontais de escamas acima da linha lateral, 8-10 abaixo; 20-24 escamas na região pré-dorsal; 21-23 séries horizontais de escamas ao redor do pedúnculo caudal; 13-16 rastros no ramo inferior do primeiro arco branquial; $19-28$ dentes no maxilar; 10-17 dentes na região posterior do dentário: 10-14 dentes no ectopterigóide.

Distribuição - Arroios, rios e lagoas da região costeira e da planície interior do Rio Grande do Sul, Brasil, Uruguai e Argentina.

A presença de $O$. jenynsii no sistema fluvial do Rio da Prata (Argentina e Uruguai) baseia-se apenas em dados da literatura. Dois exemplares recentemente coletados em um afluente do médio Uruguai, no município de Rosário do Sul, Rio Grande do Sul, não revelaram diferenças significantes em relação aos topótipos coletados em Maldonado, Uruguai e ao material da região costeira do Rio Grande do Sul; entretanto, somente uma comparação entre material do Rio da Prata (incluindo os rios Uruguai, Paraná inferior e Rio de La Plata e seus afluentes) e material da região costeira do Uruguai e Rio Grande do Sul permitirá concluir sobre a distribuição definitiva de $O$. jenynsii.

A citação de $O$. jenynsii para o Rio São Francisco (Menezes, 1969b) baseou-se em material aparentemente coletado naquele rio; isto é, havia dúvidas quanto a localidade precisa de ocorrência. Como a 
presença desta espécie na bacia do São Francisco conflita com o padrão de distribuição acima descrito, foram feitas tentativas para esclarecer a origem do material referido. Ficou constatado que os dados disponíveis são duvidosos, podendo o material em questão ser originário de outra área. Coletas recentes em vários trechos do Rio São Francisco reforçam esta suspeita, pois nunca revelaram a presença de qualquer espécie de Oligosarcus que pudesse ser identificada como 0 . jenynsii.

\section{Oligosarcus bolivianus (Fowler, 1940)}

Acestrorhamphus bolivianus Fowler 1940: 53 (localidade-tipo: Rio Lipeo, Argentina; 1950): 324 (Bolivia).

Oligosarcus bolivianus; Menezes, 1969b: 30-31 (sinonímia, descrição, distribuição); Ringuelet, Aramburu \& Aramburu, 1967: 174 (descrição, distribuição); Ringuelet, 1975: 68 (citação); Menezes \& Géry, 1983: 589, 592 (diagnose em chave, novas ocorrências).

Material examinado (4) - MZUSP 26386 (1), BM (NH) 1981. 11. 30: 20-24 (3): Rio Tomolosa, Tarija, Bolivia.

Diagnose - Nadadeira anal iv-v, 20-23; peitoral i, 13-14; 49-55 escamas perfuradas na linha lateral; $10-11$ séries horizontais de escamas acima da linha lateral, 8 abaixo; 22-23 séries horizontais de escamas ao redor do pedúnculo caudal; 14-16 rastros no ramo inferior do primeiro arco branquial; 15-24 dentes no maxilar; 10-16 dentes na região posterior do dentário; 8-13 dentes no ectopterigóide.

Distribuição Riachos formadores das drenagens dos rios Pilcomayo, Bolivia, e Bermejo, Argentina em altitudes entre 800 e 1.000 metros.

\section{Oligosarcus schindleri Menezes \& Géry, 1983}


Oligosarcus schindleri Menezes \& Géry, 1983: 566 (localidadetipo: San Francisco de Chipiriri, $100 \mathrm{~km}$ a leste de Cochabamba, Bolivia).

Material exminado (6) - MZUSP 27923: Represa México, $17 \mathrm{~km}$ ao sul de Cochabamba, Bolivia.

Diagnose Nadadeira anal iv-v, 17-19; peitoral i, 13-15; 48-54 escamas perfuradas na linha lateral; 10 séries horizontais de escamas acima da linha lateral, 7-9 abaixo; 20 escamas na região pré-dorsal; 20-21 séries horizontais de escamas ao redor do pedúnculo caudal; 12-14 rastros no ramo inferior do primeiro arco branquial; 14-17 dentes no maxilar; 10-15 dentes na região posterior do dentário; 10-14 dentes no ectopterigóide.

Distribuição Riachos da drenagem do Rio Chapare e lagoas próximas a Cochabamba, Bolivia, em altitudes de cerca de 1.500 metros.

\section{Oligosarcus paranensis Menezes \& Géry, 1983}

Oligosarcus paranensis Menezes \& Géry, 1983: 572 (localidadetipo: represa de Salesópolis, Estado de São Paulo, Brasil).

Material examinado (14) - MZUSP 19506 (2): Rio Paranapanema, Jurumirim, São Paulo; UMMZ 206192 (2): arroyo cerca de 3,3 km a oeste de Caicisa na estrada para Puerto Presidente Stroessner, Paraguai; UMMZ 206210 (7); Rio Nacunday, Puerto Presidente Stroessner, Paraguai; UMMZ 206452 (3): Rio Carapa, 1 km a oeste de Salto del Guaira, Paraguai.

Diagnose Nadadeira anal iv-v, 20-27; peitoral i, 12-16; 47-54 escamas perfuradas na linha lateral; 9-10 séries horizontais de escamas acima da linha lateral, 6-8 abaixo; 19-24 escamas na região pré-dorsal; 20-22 séries horizontais de escamas ao redor do pedúnculo caudal; 12-15 rastros no ramo inferior do primeiro arco branquial; 18-35 dentes 
no maxilar; 11-21 dentes na região posterior do dentário; 7-22 dentes no ectopterigóide.

Distribuição Bacia do Alto Paraná, em rios do Brasil e Paraguai acima de Sete Quedas.

O registro desta espécie na bacia do Rio Uruguai (Menezes \& Géry, 1983) deveu-se a identificação errônea de um exemplar de Rio das Antas (afluente do Rio Uruguai) em Santa Catarina. A constatação deste fato só foi possível depois da recente obtenção de mais exemplares da região do Alto Uruguai.

\section{Oligosarcus longirostris Menezes \& Géry, 1983}

Oligosarcus longiristris Menezes \& Géry, 1983: 576 (localidadetipo: Rio Iguaçu, Porto Lupion, Estado do Paraná, Brasil).

Oligosarcus macrolepis (non Steidachner, 1876: 594) Ringuelet, Aramburu \& Aramburu, 1967· 177 (rio Iguaçu em Misiones, Argentina).

Material examinado (1) MZUSP 35957: Rio Piraquara, afluente do Rio Iguaçu, Estado do Paraná.

Diagnose Nadadeira anal iv-v, 22-26; peitoral i, 13-15; 47-51 escamas perfuradas na linha lateral; 9-10 séries horizontais de escamas acima da linha lateral, 7-8 abaixo; 20-24 escamas na região pré-dorsal; 20-21 séries horizontais de escamas ao redor do pedúnculo caudal; 12-14 rastros no ramo inferior do primeiro arco branquial; 24-32 dentes no maxilar; 14-19 dentes na região posterior do dentário; 10-14 dentes no ectopterigóide. Focinho longo, 26,5 a $31 \%$ do comprimento da cabeça.

Distribuição - bacia do Rio Iguaçu.

Oligosarcus oligolepis (Steindachner, 1867) 
Hydrocyon hepsetus (non Cuvier, 1829: 312) Valenciennes, 1847: 9 (Buenos Aires).

Xiphorhamphus oligolepis Steindachner, 1867: 339 (localidadetipo: Rio de La Plata; tipo não visto; topótipos examinados).

Acestrorhamphus oligolepis: Eigenmann, 1910: 447 (citação); Pozzi, 1945: 257 (citação); Ringuelet, Aramburu \& Aramburu, 1967: 177 (descrição, distribuição); Ringuelet, 1975: 65 (citação).

Acestrorhynchus oligolepis; De Buen, 1950: 85.

Sphyraenocharax oligolepis; Fowler, 1950: 327 (citação); Ringuelet \& Aramburu, 1962: 32 (citação).

Xiphorhamphus jenynsii (non Günther, 1864: 356) Günther, 1880: 13 (Rio de La Plata).

Xiphorhamphus hepsetus (non Cuvier, 1829: 312) Steindachner, 1891: 371 (em parte; apenas exemplares do Arroyo Miguelete); Lahille, 1895: 272 (Punta Lara; Isla Santiago; citação); Marelli, 1924: 560 (Rio de La Plata, Provincia de Buenos Aires; Isla Santiago; Punta Lara; Arroyo Tafalque).

Acestrorhamphus hepsetus; Eigenmann \& Kennedy, 1903: 527 (Asunción); Eigenmann, 1907: 452 (citação); Mac Donagh, 1938: 97 (Rio IV, Cordoba); 1940: 95 (citação); Ringuelet, 1940: 105 (Rosario); 1975: 61, 65, 79 (citação); Devicenzi \& Teague, 1942: 82 (Rio Uruguai); Pozzi, 1945: 257 (citação); Aramburu, 1953: 311 (descrição); Ringuelet \& Aramburu, 1957: 12 (Paraná-Plata); 1962: 31 (citação); Ringuelet, Aramburu \& Aramburu, 1967: 174 (descrição, distribuição); Boschi \& Fuster de Plaza, 1959: 24 (Lago Embalse, Rio III).

Acestrorhynchus hepsetus; Devicenzi, 1924: 178 (Arroyo Miguelete); De Buen, 1950: 85.

Oligosarcus hepsetus; Menezes, 1969b: 22, 23 (parte; apenas exemplares de Buenos Aires, Argentina e Itaqui, Rio Grande do Sul).

Oligosarcus robustus (non Menezes, 1969b) Menezes 1969b: 26, 27 (parte; apenas exemplares de Salto Chico, Rio Uruguai; Ringuelet, 1975: 65 citação). 
Material examinado (15) MZUSP 37264 (2): Arroio do Salso, afluente do Rio Ibicui, Rosario do Sul, Rio Grande do Sul; MZUSP 37263 (3): Sanga das Águas Frias, Iraí, Rio Grande do Sul; MZUSP 37265 (1): Rio Piratini, afluente do Rio Uruguai, Santo Ângelo, Rio Grande do Sul; UMMZ 206389, 206492, 206500, 206534 (6): Rio Jejui-Guazu, Departamento Canendiyu, Paraguai; UMMZ 206844 (3): Arroyo Pindo, Departamento San Pedro /Caraguazu, Paraguai.

Diagnose Nadadeira anal iv-v, 25-29; peitoral i, 13-16; 71-81 escamas perfuradas na linha lateral; $14-16$ séries horizontais de escamas acima da linha lateral, 10-13 abaixo; 27-35 escamas na região pré-dorsal; 25-28 séries horizontais de escamas ao redor do pedúnculo caudal; 14-16 rastros no ramo inferior do primeiro arco branquial; 23-31 dentes no maxilar; 14-22 dentes na região posterior do dentário; $13-20$ dentes no ectopterigóide.

Distribuição - Rios Paraguai, Paraná inferior, Uruguai e La Plata e seus afluentes da parte baixa.

\section{Oligosarcus robustus Menezes, 1969}

Xiphorhamphus hepsetus (non Cuvier, 1829: 312) Hensel, 1870: 88- 89 (Rio Guaiba, Rio Grande do Sul; descrição); Ihering, 1893: 26; 1897: 21 (Rio Grande do Sul; diagnose); Cope, 1894: 85 (Rio Grande do Sul).

Acestrorhamphus hepsetus; Fowler, 1906 (Rio Grande do Sul): Gomes, 1947 22 (Lagoa dos Quadros, Rio Grande do Sul).

Acestrorhamphus sp. A. Menezes, 1969a: 219, 221.

Oligosarcus robustus Menezes, 1969b: 26 (localidade-tipo: Rio Caí, afluente do Rio Guaiba, Montenegro, Rio Grande do Sul); Menezes \& Géry, 1983: 589 (diagnose em chave).

Material examinado (28): Rio Grande do Sul - MZUSP 19733 (2), 19736 (3), Rio dos Sinos, São Leopoldo; MZUSP 14191 (2), Lagoa dos 
Quadros, Osório; MZUSP 19574 (1), Açude Lomba do Sabão, Porto Alegre; MZUSP 19965 (1), Arroio Chasqueiro, rodovia Pelotas - Jaguarão; MZUSP 19882 (5), arroio no município de Belém Novo, perto de Porto Alegre; MZUSP 19876 (10), Arroio Chapéu Virado, município de Belém Novo; MZUSP 19923 (1), Arroio Paradiso, estrada São Sebastião do Caí - Bom Princípio; MZUSP 20002 (3), Lagoa Mirim em Ponta Alegre.

Diagnose - Nadadeira anal iv-v, 24-29; peitoral i, 12-16; 75-85 escamas perfuradas na linha lateral; $16-18$ séries horizontais de escamas acima da linha lateral, 11-15 abaixo; 38-42 escamas na região pré-dorsal; 28-32 séries horizontais de escamas ao redor do pedúnculo caudal; 14-17 rastros no ramo inferior do primeiro arco branquial; 23-36 dentes no maxilar; 12-23 dentes na região posterior do dentário; 11-21 dentes no ectopterigóide.

Distribuição Arroios, rios e lagoas da região litirânea do Rio Grande do Sul não pertencentes à bacia do Rio Uruguai.

\section{Oligosarcus hepsetus (Cuvier, 1829)}

Hydrocyon falcatus (non Bloch, 1794) Quoy \& Gaimard, 1824: 222 (Rio de Janeiro).

Hydrocyon hepsetus Cuvier, 1829: 312 (localidade-tipo: Brasil, Rio de Janeiro).

Xiphorhamphus hepsetus; Müller \& Troschel, 1844: 39; 1845: 18 (América do Sul); Günther, 1864: 356 (Rio de Janeiro; descrição); Steindachner, 1876: 593 (parte; apenas exemplares do Rio Paraiba e do Rio Piabanha); 1891: 371 (parte; apenas exemplares do Rio Paraiba); Eigenmann \& Eigenmann, 1891: 58 (citação); Boulenger, 1896: 154 (Colonia Alpina, Rio de Janeiro).

Xiphorhynchus hepsetus; Valenciennes, 1849: 343 (Rio de Janeiro). 
Acestrorhamphus hepsetus; Eigenmann, 1910: 447 (citação); Campos, 1945: 481 (parte; apenas exemplares de Rio Juquiá); Fowler, 1950: 325 (sinonímia); Fernandez-Yepez, 1955: 5 (diagnose); Géry, 1960: 278 (Rio Humboldt, Santa Catarina; descrição); Menezes, 1969a: 218,221 .

Oligosarcus hepsetus; Menezes, 1969b: 22 (parte; apenas exemplares coletados entre Santa Catarina e Rio de Janeiro); Menezes \& Géry, 1983: 589 (diagnose em chave).

Acestrorhamphus macrolepis (non Steindachner, 1876) Campos, 1945: 482 Juquiá, São Paulo).

Acestrorhamphus pericoptes (non Müller \& Troschel, 1844) Campos, 1945: 482 (Lagoa Feia, Rio de Janeiro).

Oligosarcus jenynsii (non Günther, 1864) Menezes, 1969b: 16 (parte; apenas exemplares coletados entre São Paulo e Rio de Janeiro).

N O T A Xiphorhamphus pericoptes Müller \& Troschel, 1844, colocado por Menezes (1969b: 23) na sinonímia de Oligosarcus hepsetus (Cuvier) é aquí considerado um "nomen dubium" Os dados merísticos e morfométricos da descrição original indicam uma possível identidade de $X$. pericoptes tanto com $O$. hepsetus (Cuvier) como com $O$. robustus (Menezes).

Embora estas duas espécies ocupem áreas geográficas distintas, não é possível restringir a localidade-tipo de $X$. pericoptes a uma delas, pois, como procedência do material-tipo, consta apenas Brasil e Friedrich Sello, coletor deste material segundo Müller \& Troschel, coletou tanto na área de distribuição de $O$. hepsetus como na de $O$. robustus durante sua estada no Brasil (Papavero, 1971). O holótipo, depositado no Museu de Berlim, foi destruido durante a segunda guerra mundial.

Material examinado (28) - MZUSP 20504 (7): Rio Cubatão, perto de Joinvile, Santa Catarina; MZUSP 20489 (3): Córrego afluente do Rio Nhundiaquara, Paraná; MZUSP 20493 (1): Morretes, Paraná; MZUSP 30956 (1): Rio do Meio, Antonina, Paraná; MZUSP 35955 (2): Guaraqueçaba, Paraná; MZUSP 19873 (3); Rio Jacupiranga, São Paulo; 
MZUSP 19507 (5): alfuente do Rio Paraitinga, Redenção da Serra, São Paulo; MZUSP 26876 (3): Reservatório de Jaguari, Igaratá, São Paulo; MZUSP 26857 (3): Rio Guapiaçu, Cachoeiras de Macacu, Rio de Janeiro.

Diagnose Nadadeira anal iv- $v, 26-32$; peitoral i, 12-15; 60-75 escamas perfuradas na linha lateral; $12-15$ séries horizontais de escamas acima da linha lateral, 9-12 abaixo; 23-28 escamas na região pré-dorsal; 23-28 séries horizontais de escamas ao redor do pedúnculo caudal; 12-16 rastros no ramo inferior do primeiro arco branquial; 21-35 dentes no maxilar; 11-23 dentes na região posterior do dentário; 10-22 dentes no ectopterigóide.

Distribuição - Lagoas e rios da região costeira do sudeste brasileiro entre Santa Catarina e Rio de Janeiro.

\section{Oligosarcus planaltinae Menezes \& Géry, 1983}

Oligosarcus planaltinae Menezes \& Géry, 1983: 564 (localidadetipo: Córrego Planaltina, afluente do Rio São Bartolomeu, perto de Brasilia, estado de Goiás).

Material examinado (3) MZUSP 38083 (2): Córrego Taboca, afluente do Rio São Bartolomeu, perto de Brasilia, D.F.; MZUSP 38084(1): Ribeirão Santana, aflunte do Rio São Bartolomeu, perto de Brasília, D.F.

Diagnose Nadadeira anal iv-v, 24-26; peitoral i, 13-14; 38-40 escamas perfuradas na linha lateral; 8 séries horizontais de escamas acima da linha lateral, 7 abaixo; cerca de 15 escamas na região pré-dorsal; 17 séries horizontais de escamas ao redor do pedúnculo caudal; 13-14 rastros no ramo inferior do primeiro arco branquial; 24-27 dentes no maxilar; 13-16 dentes na região posterior do dentário; 10-18 dentes no ectopterigóide.

Distribuição - afluentes do Rio São Bartolomeu, bacia do Rio Paranaiba, estado de Goiás. 


\section{CHAVE ARTIFICIAL PARA AS ESPÉCIES DO GêNERO OLIGOSARCUS}

1 - Dentes tricuspidados no pré-maxilar, tricuspidados a pentacuspidados no dentário; mandíbula saliente, ligeiramente mais longa que a maxila superior quando a boca está fechada (bacia do Alto Paraná, acima de Sete Quedas, em rios do Brasil e Paraguai)........................................................................ O. pintoi

Dentes cônicos a fracamente tricuspidados no pré-maxilar, maxilar e dentário; mandíbula igual ou ligeiramente mais curta que a maxila superior quando a boca está fechada.

2 - Escamas relativamente grandes; 38-48 escamas perfuradas na linha lateral (cabeceiras do Rio Paranaíba no estado de Goiás) O. planaltinae

Escamas relativamente pequenas; 44-83 escamas perfuradas na linha lateral

3 Nadadeira anal com 17-19 raios ramificados (lagoas e riachos perto de Cochabamba, Bolívia). O. schindleri

Nadadeira anal com $20-30$ raios ramificados

4 12-18 séries horizontais de escamas entre a linha lateral e a origem da nadadeira dorsal

811 séries horizonais de escamas entre a linha lateral e a origem da nadadeira dorsal

5 17-20 (geralmente menos que 20) séries horizontais de escamas ao redor do pedúnculo caudal

20-23 (geralmente mais que 20) séries horizontais de escamas ao redor do pedúnculo caudal 
6 24-35 dentes no maxilar; 13-15 rastros no ramo inferior do primeiro arco branquial (lagos do Vale do Rio Doce em Minas Gerais) O. solitarius, sp.n. 13-25 dentes no maxilar; 11-14 rastros no ramo inferior do primeiro arco branquial 7

7 - 44-48 escamas perfuradas na linha lateral; 17-20 escamas na região pré-dorsal 8 47-56 escamas perfuradas na linha lateral; 18-23 escamas na região pré- dorsal (Alto Rio Uruguai). O. brevioris, sp.n.

8 - Comprimento padrão dos maiores exemplares adultos atingindo $77 \mathrm{~mm}$; 25-27 raios ramificados na nadadeira anal (partes média e superior do Rio Jequitinhonha).................................. O. macrolepis Comprimento padrão dos maiores exemplares adultos atingindo 162 $\mathrm{mm}$; 20-25 raios ramificados na nadadeira anal (cabeceiras do Rio Doce e do Rio das Velhas em Minas Gerais). O. argenteus

9 - 54-62 escamas perfuradas na linha lateral; 8-10 séries horizontais de escamas entre a linha lateral e a origem da nadadeira anal (rios e lagoas da região litorânea e planície interior do estado do Rio Grande do Sul, Brasil, do Uruguai e Argentina).............................. O. jenynsii 47-58 escamas perfuradas na linha lateral; 6-9 séries horizontais de escamas entre a linha lateral e a origem da nadadeira anal 10

10 - 25-30 raios ramificados na nadadeira anal (lagoas e rios costeiros do Brasil entre o Rio de Janeiro e o sul da Bahia) O. acutirostris, sp.n. 
11 - 22-23 séries horizontais de escamas ao redor do pedúnculo caudal; 10-11 séries horizontais de escamas entre a origem da nadadeira dorsal e a linha lateral (cabeceiras do Rio Bermejo, Argentina e Pilcomayo, Bolívia). O. bolivianus 20-22 séries horizontais de escamas ao redor do pedúnculo caudal; 9-10 séries horizontais de escamas entre a origem da nadadeira dorsal e a linha lateral 12

12 Focinho curto, cerca de 22 a 29\% do comprimento da cabeça, 38 vértebras (bacia do Alto Paraná acima de Sete Quedas, em rios do Brasil e Paraguai). O. paranensis Focinho longo, cerca de 26,5 a $31 \%$ do comprimento da cabeça; 39 vértebras (bacia do Rio Iguaçu). O. longirostris

13 -23-28 escamas na região pré-dorsal; 60-75 escamas perfuradas na linha lateral; 12-15 séries horizontais de escamas entre'a origem da nadadeira dorsal e a linha lateral (rios e lagoas da região costeira do Brasil entre Santa Catarina e Rio de Janeiro) O. hepsetus 27-42 escamas na região pré-dorsal; 71-85 escamas perfuradas na linha lateral; $14-18$ séries horizontais de escamas entre a origem da nadadeira dorsal e a linha lateral

14 - 25-28 séries horizontais de escamas ao redor do pedúnculo caudal; 27-35 escamas na região pré-dorsal; 14-16 séries horizontais de escamas entre a origem da nadadeira dorsal e a linha lateral (Rio Paraguai, baixo Paraná, Rio Uruguai e Rio de La Plata) O. oligolepis 28-32 séries horizontais de escamas ao redor do pedúnculo caudal; 38-42 escamas na região pré-dorsal; $16-18$ séries horizontais de escamas entre a origem da nadadeira dorsal e a linha lateral (rios e lagoas da região litorânea e planície interior do Rio Grande do Sul)

O. robustus 


\section{REFERÊNCIAS BIBLIOGRÁFICAS}

BOSCHI, E.E. \& FUSTER DE PLAZA, M.L. 1959 Estudio biológico pesquero del Pejerrey del Embalse del rio III (Basilichthys bonariensis) con una contribución al conocimiento limnológico del ambiente. Dep.Invest.Pesq., An.Sec.Agric.Ganad., B.Aires (8): 1-16. DE BUEN, F. 1950 El mar de solís y su fauna de peces (segunda parte). Publ. Cient. Serv. Oceanogr. y Pesca del Uruguay (2): 46- 144.

FINK, W.L. \& S.H.WEITZMAN 1974. The so-called cheirodontin fishes of Central America with descriptions of two new species (Pisces: Characidae). Smithson.Contr. Zool., Washington, D.C. 172: 1-46.

GODOY, M.P. De 1971. Descoberta do gênero Hemibrycon Günther, 1864 na bacia do Rio Mogi-Guassu (Rio Paraná, Bacia Superior). I Descrição de Hemibrycon marciai sp.n. (Pisces, Characidae, Heterognathi). Rev. bras. Biol., R. Janeiro, 31(2) :153-9.

GODOY, M.P. De 1975. Peixes do Brasil, subordem Characoidei, Bacia do Rio Mogi-Guassu. 2: vi+217-398 pp. Ed. Franciscana, Piracicaba,SP.

HOLMBERG, E.E. 1889 Nombres vulgares de peces argentinos con sus equivalencias científicas. Rev. Soc. Georg. Argent., 6(62): 3611-378. HOLMBERG, E.E. 1893 Nombres vulgares de peces argentinos con sus equivalencias científicas. Rev. Jard.zool., B.Aires, 1: 85-96.

LAHILLE, F. 1985 Faunas locales argentinas. I. Lista de pescados recogidos en los alrededores de La Plata (Prov. de Buenos Aires) durante el año 1894, y conservados en las coleciones del Museo de La Plata. Rev. Mus. La Plata, 6: 265- 274.

MAC DONAGH, E.G. 1938 Sobre estudios en el Paraná sur de Cordoba y región de Uspallat. Rev. Mus. La Plata. n.s., Sec. of 1937 89-100. MAC DONAGH, E.G 1940 Estudios zoológicos en las provincias de Buenos Aires Y Cordoba. Rev. Mus. La Plata, n.s., Sec. Of. 1939: 85-104. 
MARELLI, C.A. 1924 Elenco sistemático de la fauna de la Provincia de Buenos Aires (Procordados Y Vertebrados). Mem. Min. Obras Publ., Montevideo, 1922-1923: 536-682.

MENEZES, N.A. 1969a The food of Brycon and three closely related genera of the tribe Acestrorhynchini. Pap. Avul. Zool., S.Paulo, S.P., 22: 217-223.

MENEZES, N.A. 1969b Systematics and evolution of the tribe Acestrorhynchini (Pisces, Characidae). Arq.Zool., S.Paulo,S.P., 18(1- 2): 1-150.

MENEZES, N.A. 1988 Implications of the distribution patterns of the species of Oligosarcus (Teleostei, Characidae) from cental and southern South America. pp. 295-304 In: HEYER, W.R. \& VANZOLINI, P.E. EDS., Proceedings of a Workshop on Neotropical Distribution Patterns.

MENEZES, N. A. \& J. GÉRY 1983 Seven new acestorhynchin characid species (Osteichthyes, Ostariophysi, Characiformes) with comments on the systematics of the group. Rev. suisse Zool., Genéve, 90(3): 563-592.

MIQUELARENA, A.M. 1986 Estudio de la dentición en peces caracoideos de la Republica Argentina. Biol. Aquatica, (8): 1-60.

OLIVIER, S.R. 1961 Estudios limnológicos en la laguna Vitel (partido de Chascomus, Buenos Aires, Argentina). Agro, (6): 1-128.

PAPAVERO, N. 1971. Essays on the history of Neotropical Dipterology, with reference to collectors (1750-1905). 1: 216p. Mus.Zool. Univ.S.Paulo.

RINGUELET, R.A. 1940 La estación Hidrobiológica de Rosario. Notas Mus. La Plata 5 (34): 95-109.

RINGUELET, R.A. 1975 Zoogeografia y ecologia de los peces continentales de la Argentina y consideraciones sobre las áreas ictiológicas de América del Sur. Ecosur, 2(3): 1-122.

RINGUELET, R.A.\& R.H. ARAMBURU, 1957 Enumeración sistemática de los Vertebrados de la Provincia de Buenos Aires. Min. As. Agr. Pcia. Buenos Aires (119): 1-92. 
RINGUELET, R.A., R.H. ARAMBURU \& A.A DE ARAMBURU. 1967 Los peces argentinos de agua dulce. Com. Invest. Cient. Prov. Buenos Aires, La Plata, 602 pp.

RINGUELET, R.A., S.R. OLIVIERI, S.A. GUARRERA \& R.H.ARAMBURU 1955 Observaciones sobre autoplancton y mortandad de peces en la laguna de Monte (Buenos Aires, Rep. Argentina). Notas Mus. La Plata (Zool.) 18(159): 71-80.

SCHUBART, O. 1962 Lista dos peixes da bacia do Rio Mogi-Guassu. Atas Soc. Biol. R. Janeiro 6(3): 26-32. 